NOTES

\title{
Mechanical Properties of Composite Hydrogels
}

\author{
Shoji NAGAOKA \\ Basic Research Laboratories, Toray Industries, Inc., \\ 1111 Tebiro, Kamakura 248, Japan
}

(Received March 22, 1989)

\begin{abstract}
KEY WORDS Hydrogel / $N$-Vinyl-2-pyrrolidone / Snake-Cage Polymer / Mechanical Properties /
\end{abstract}

As polymers are increasingly used in medical applications, hydrophilic polymers, or hydrogel, have become of major interest. Hydrogel is now being used for membranes, catheters, contact lenses, and materials for drug delivery systems. The most representative hydrogel is poly(2-hydroxyethyl methacrylate) (PHEMA). ${ }^{1}$ Hydrogel with a higher water content is generally more advantageous in increasing permeability and biocompatability. However, increasing the water content weakens the mechanical strength of the hydrogel, and may also reduce the transparency of the gel as a result of macroscopic phase separation between water and polymer.

To achieve high mechanical strength and transparency while maintaining a high water content, composite structure in the molecular level, consisting of a hydrophilic component which absorbs large amounts of water, and a hydrophobic component which contributes mechanical strength, is necessary for the hydrogel.

Snake-cage polymerization method ${ }^{2}$ is useful to obtain such a hydrogel. We synthesized hydrogels of cross-linked $N$-vinyl-2-pyrrolidone (cage) in which linear hydrophobic polymer (snake) with excellent mechanical properties was entrapped. Their physical properties were then studied.

\section{EXPERIMENTAL}

\section{Polymerization}

$N$-Vinyl-2-pyrrolidone (NVP, GAF) was distilled in vacuum. The hydrophobic polymers used were poly(methyl methacrylate) (PMMA, Mitsubishi Rayon Co.), poly(vinyl chloride) (PVC, Japan Zeon), poly(vinyl butyral) (PVB, Denki Kagaku Ind.), cellulose acetate (CA, acetyl content $39.8 \%$, Eastman Kodak), polyurethane (PU, Uniroyal, Inc.), and polystyrene (PS, Mitsui Chem. Inc.). These polymers were refined once by reprecipitation with a solvent-nonsolvent system.

To inhibit interpolymer phase separation under high temperatures, photoinitiated polymerization at low temperature was conducted by using benzoin ethyl ether (Wako Chemistry) with a concentration of $10^{-3}$ mol $1^{-1}$ as a photosensitizer. Diethylenglycol dimethacrylate (2G, Nippon Oil Co.) was used as a crosslinking agent for NVP.

A sepcified quantity of hydrophobic polymer was dissolved in NVP containing a specified quantity of crosslinked agent. The resulting mixture was filtered through a Teflon membrane (pore size: $1 \mu \mathrm{m}$ ) filter under pressure.

The filtered solution was injected into an $18 \mathrm{~mm}$ diameter, pyrex test tube. After the substitution of air by argon, photoinitiated 
polymerization was initiated. A $100-\mathrm{W}$ high pressure mercury lamp (Ushio, UM-102) was used as a light source. The distance between lamp and test tube was $25 \mathrm{~cm}$, and the test tube was rotated at a rate of $1 \mathrm{rpm}$. The polymerization temperature was $10^{\circ} \mathrm{C}$, and the polymerization time ws $24 \mathrm{~h}$.

The resultant polymer was heated at temperatures between 90 and $100^{\circ} \mathrm{C}$ for $24 \mathrm{~h}$ to complete the polymerization. Crosslinked poly NVP and PHEMA were obtained in a similar manner. 2-Hydroxyethyl methacrylate was supplied by Tokyo Kasei Co.

\section{Specimen Preparation}

After heat treatment, the polymer block was removed, lathed nd polished with highprecision to create a $0.10-0.15 \mathrm{~mm}$ thick, flat, membrane-type specimen.

\section{Measurements of Physical Properties of the Hydrogel \\ (1) Water Content. The water content $(W)$ of the testing material (membrane) after hy- dration in normal saline solution for $24 \mathrm{~h}$ at $37^{\circ} \mathrm{C}$ was determined as follows:}

$$
W(\%)=\frac{\text { Weight of wet membrane }- \text { Weight of dry membrane }}{\text { Weight of wet membrane }} \times 100
$$

(2) Mechanical Properties. The hydrated gel as described above was subjected to a tensile test by using Shimadzu IM-100 Instron to determine tensile strength $\left(\sigma_{\mathrm{b}}\right)$, elongation $\left(\varepsilon_{\mathrm{b}}\right)$, and initial tensile modulus $\left(E_{0}\right)$.

Measurements were taken with the specimen soaked in a $37^{\circ} \mathrm{C}$ normal saline solution. The tensile speed was $10 \mathrm{~cm} \mathrm{~min}^{-1}$.

(3) Transparency. A visible ultraviolet spectrophotometer (Shimadzu UV-300) was used to measure the transmittance of visible light $(500 \mathrm{~nm})$ through the hydrated specimen with a specified thickness.

(4) Water Resistance. The hydrated specimen was allowed to boil for $24 \mathrm{~h}$ and the change in weight of the dried gel was measured.

(5) Water Permeability. ${ }^{3}$ The water permeability coefficient $L_{\mathrm{p}}$ is defined by:

$$
J_{\mathrm{v}}=L_{\mathrm{p}} \cdot \Delta P
$$

where $J_{v}$ and $\Delta P$ are volume flux of water $\left[\mathrm{cm}^{3}\left(\mathrm{~cm}^{2} \mathrm{~s}\right)^{-1}\right]$ and pressure difference (dyn $\mathrm{cm}^{-2}$ ) across the membrane, respectively. $L_{\mathrm{p}}$ was measured by using a batch filtering cell and at a water head of $1 \mathrm{~m}$ as $\Delta P$.

\section{RESULTS AND DISCUSSION}

\section{Mechanical Properties of Snake-Cage Hydro-} gels

NVP is a good solvent for a wide variety of polymers as well as $N$-methyl pyrrolidone (NMP). PMMA, PVC, PVB, CA, PU, and PS were soluble in NVP and produced transparent hydrogel after photoinitiated crosslink polymerization of NVP.

As a result of preliminary studies of mechanical properties, it was revealed that promising linear hydrophobic polymers were PMMA and CA. Figures $1-3$ show the mechanical properties, namely tensile strength, elongation at break, and initial tensile modulus of the hydrogels containing PMMA and CA. As indicated in Figures 1-3, hydrogels which had a water content ranging from 70 to $90 \%$ were obtained by changing the amount of hydrophobic polymer under constant amounts of cross-linking agent $(0.1 \mathrm{~mol} \%$ to NVP).

The mechanical properties of the hydrogels decreased with the increasing water content because water virtually does not contribute to the mechanical properties. However, the hydrogels with water content around $75 \%$, which is much higher than PHEMA $(W=39 \%)$, showed superior mechanical strength and 


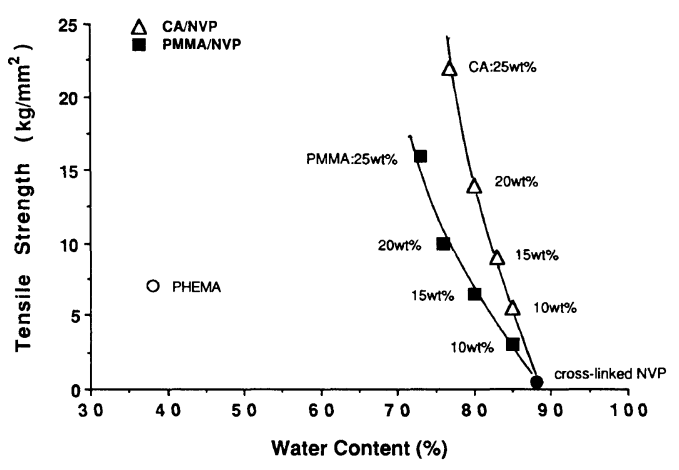

Figure 1. Relationship between water contents of various snake-cage hydrogels with NVP network and their tensile strength: in $37^{\circ} \mathrm{C}$ physiological saline solution.

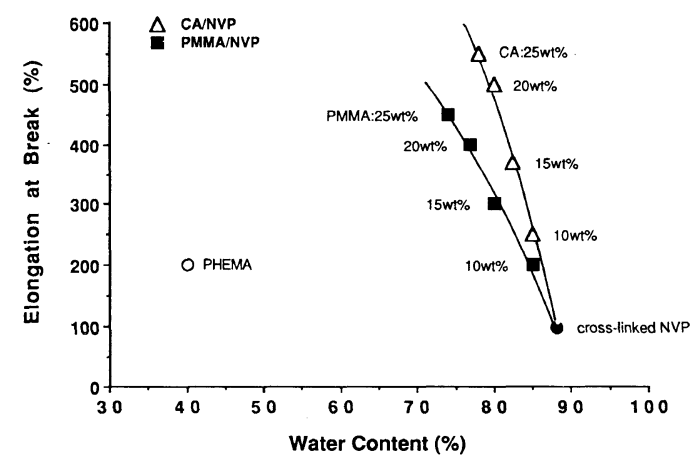

Figure 2. Relationship between water contents of various snake-cage hydrogels with NVP network and their elongation at break: in $37^{\circ} \mathrm{C}$ physiological saline solution.

elongation to those of PHEMA. The transmittance of visible light $(500 \mu \mathrm{m})$ of these hydrogels with thickness of $100 \mu \mathrm{m}$ were above $98 \%$.

These results suggest that the expected composite structures in molecular level were formed in the case of PMMA/NVP and CA/ NVP systems.

Snake-cage hydrogels with CA as a hydrophobic component (CA/NVP snake-cage hydrogel) showed excellent mechanical properties and transprency and detailed research on the CA/NVP snake-cage hydrogel was conducted to determine the optimal composition.

Major factors affecting the physical properties of CA/NVP snake-cage hydrogel are the

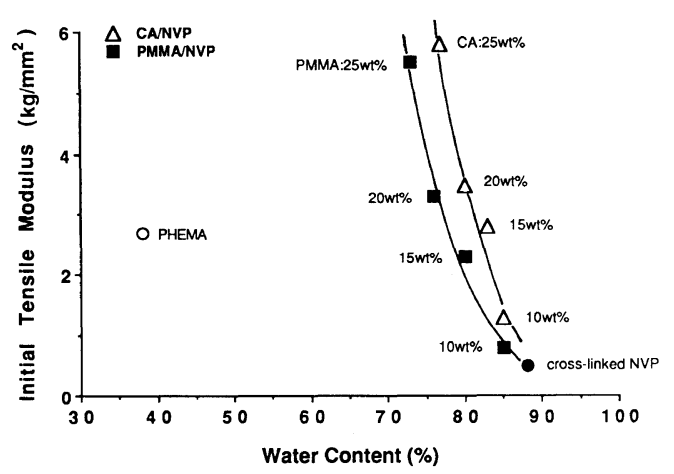

Figure 3. Relationship between water contents of various snake-cage hydrogels with NVP network and their initial tensile modulus: in $37^{\circ} \mathrm{C}$ physiological saline solution.

amount of CA and crosslinking agent added. As is evident from Figures 1 and 2, increasing the amount of $\mathrm{CA}$ added under constant amount of crosslinking agent $(0.1 \mathrm{~mol} \%$ to NVP) improved the mechanical strength and elongation of hydrogels.

However, as shown in Figure 3, it increased the initial tensile modulus (a parameter of softness of the hydrogels), which is unfavorable for living tissue and mucous membranes. It also increased the viscosity of the feeding solution for polymerization, which made it harder to filter and defoam. The abovementioned results revealed that the upper limit of the amount of CA was $25 \mathrm{wt} \%$.

Figures 4 and 5 show the relationship between the amount of crosslinking agent added and the physical properties of hydrogel containing a constant quantity (20 and $25 \mathrm{wt} \%$ ) of CA. Increasing the amount of crosslinking agent improved the water resistance of hydrated gel due to the tight network formation. However, excessive amounts of crosslinking agent caused the hydrated gel to become brittle and decreased its tensile strength. These results revealed that the optimal amount of crosslinking agent is between 0.1 and $0.3 \mathrm{~mol}^{\circ} \%$ to NVP. 


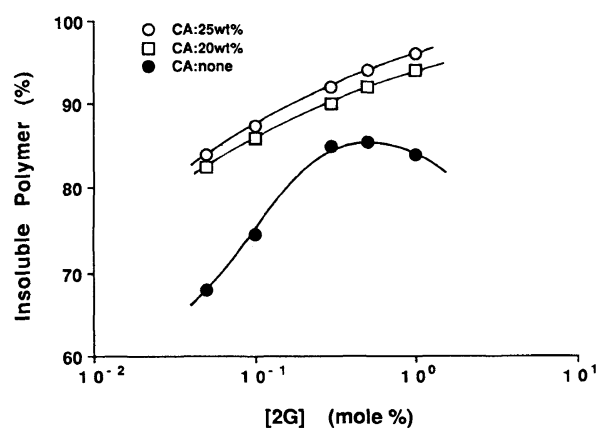

Figure 4. Relationship between the amount of crosslinking agent and the water resistance of the CA/NVP snake-cage hydrogels.

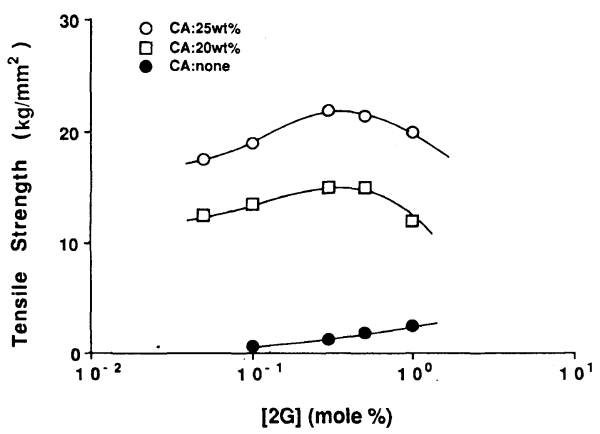

Figure 5. Relationship between the amount of crosslinking agent and the tensile strength of the CA/NVP snake-cage hydrogels.

Table I. Water permeability of hydrogels

\begin{tabular}{|c|c|c|c|}
\hline \multirow{2}{*}{ Hydrogel } & Water content & Mechanical strength & Water permeability $\left(\lambda L_{p}\right)$ \\
\hline & $\%$ & $\mathrm{~kg} \mathrm{~mm}^{-2}$ & $\mathrm{~g}^{-1} \mathrm{~cm}^{3} \mathrm{~s}^{-1}$ \\
\hline $\begin{array}{r}\text { CA/NVP snake-cage } \\
(\mathrm{CA} / \mathrm{NVP}=15 / 85)\end{array}$ & 82 & 9.2 & $9.3 \times 10^{-13}$ \\
\hline PHEMA & 39 & 7.0 & $8.7 \times 10^{-14}$ \\
\hline
\end{tabular}

Permeability of CA/NVP Snake-Cage Hydrogel

One of the advantageous physical properties of the hydrogels is the permeability (such as water or oxygen permeability). Permeability of hydrogels depends mainly on the water content rather than the type of polymer itself. Table I shows the water permeability of CA/NVP snake-cage polymers as compared with PHEMA. CA/NVP snake-cage hydrogel, with the similar tensile strength to PHEMA, showed more than 10 times greater water permeability than PHEMA because it has a much higher water content $(82 \%)$ than that of PHEMA $(39 \%)$.

\section{CONCLUSION}

It is possible to produce hydrogel with high transparency, high water content, and excellent mechanical properties by using the snakecage polymerization method. Especially, crosslinking polymerization of NVP in the presence of cellulose acetate enables us to create a new snake-cage hydrogel, which showed excellent mechanical properties and water permeability compared with PHEMA. It is a promising material for membranes, soft contact lenses, and drug delivery systems.

\section{REFERENCES}

1. O. Wichterle and D. Lim, Nature, 185, 117 (1960).

2. R. Jerome and V. Desreux, J. Appl. Polym. Sci., 15, 199 (1971).

3. Y. Sakai and H. Tanzawa, J. Appl. Polym. Sci., 22, 1805 (1978). 